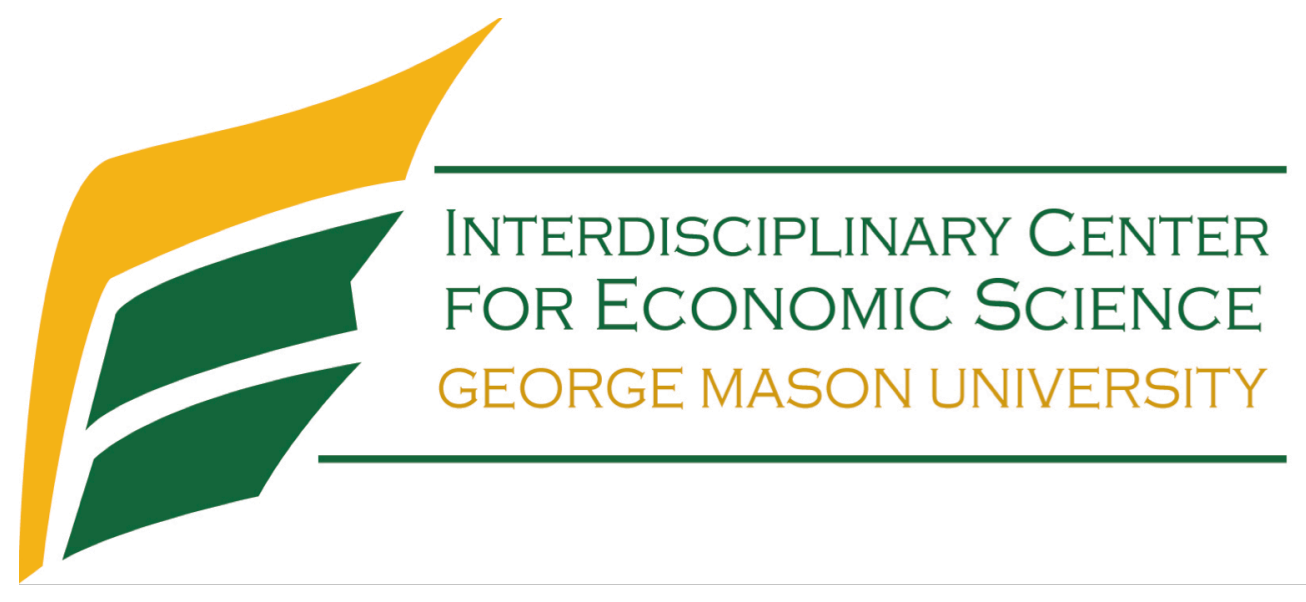

\title{
Dishonesty: From Parents to Children
}

Daniel Houser, John A. List, Marco Piovesan, Anya Samek, and Joachim Winter

September 2015

Discussion Paper

Interdisciplinary Center for Economic Science

4400 University Drive, MSN 1B2, Fairfax, VA 22030

Tel: +1-703-993-4719 Fax: +1-703-993-4851

ICES Website: $h$ ttp://ices.gmu.edu

ICES RePEc Archive Online at: http://edirc.repec.org/data/icgmuus.html 


\title{
Dishonesty: From Parents to Children
}

\author{
Daniel Houser ${ }^{\mathrm{a}}$, John A. List ${ }^{\mathrm{b}}$, Marco Piovesan ${ }^{\mathrm{c}}$, Anya Samek ${ }^{\mathrm{d}}$ and Joachim Winter ${ }^{\mathrm{e}}$ \\ ${ }^{a}$ Department of Economics, George Mason University \\ ${ }^{\mathrm{b}}$ Department of Economics, University of Chicago \\ ${ }^{c}$ Department of Economics, University of Copenhagen \\ ${ }^{\mathrm{d}}$ Center for Economic and Social Research, University of Southern California \\ ${ }^{\mathrm{e}}$ Department of Economics, University of Munich
}

September 2015

\begin{abstract}
Acts of dishonesty permeate life. Understanding their origins, and what mechanisms help to attenuate such acts is an underexplored area of research. This study takes an economics approach to explore the propensity of individuals to act dishonestly across different contexts. We conduct an experiment that includes both parents and their young children as subjects, exploring the roles of moral cost and scrutiny on dishonest behavior. We find that the highest level of dishonesty occurs in settings where the parent acts alone and the dishonest act benefits the child. In this spirit, there is also an interesting, quite different, effect of children on parents' behavior: parents act more honestly under the scrutiny of daughters than under the scrutiny of sons. This finding sheds new light on the origins of the widely documented gender differences in cheating behavior observed among adults, where a typical result is that females are more honest than males.
\end{abstract}

\section{JEL Classifications: C91, D63}

Keywords: cheating, dishonesty, ethical judgment, social utility, field experiment

Corresponding author: Anya Samek, anyasamek@gmail.com

* We thank the Becker Friedman Institute staff and our 2011 summer interns for help in conducting experiments, especially Jennie (Jai) Huang. We thank Lydia Zepeda for valuable input. This research is based on work supported by the Kenneth and Anne Griffin Foundation and the John Templeton Foundation. Any opinions, findings, and conclusions expressed in this paper are the views of the authors and do not reflect the views of the funding agencies. 


\section{Introduction}

Individuals encounter opportunities to act dishonestly for personal gain in all areas of life. People cheat on taxes, over-charge clients, steal from the workplace, download music and movies from the Internet illegally, and use public transportation without paying the fare. Such 'small scale but mass cheating' (Ariely, 2012) acts have great social and economic costs. ${ }^{1}$ In addition to the direct pecuniary cost to business and government, the prevalence of dishonesty has detrimental impacts on the inner workings of modern economies. As expressed by Arrow over three decades ago, "Virtually every commercial transaction has within itself an element of trust ... It can be plausibly argued that much of the economic backwardness of the world can be explained by a lack of mutual confidence" (Arrow, 1972, p 357).

While economists have made important strides to explore the prevalence and importance of dishonesty (see, e.g., Gneezy, 2005, Sutter, 2009, Cappelen, Sorensen, and Tungodden, 2013), understanding how such acts arise and what economic environments attenuate or exacerbate their prevalence is an underexplored area of research. ${ }^{2}$ We propose that both moral cost and scrutiny are key features affecting whether or not an individual will act dishonestly, and that these factors yield predictions regarding the influence of various contextual features on dishonest behaviors. We also posit that parental influence on children is one channel through which attitudes towards dishonesty develop.

We designed a field experiment in which parents of 3-6 year-old children have the possibility to increase their payoffs by misreporting the outcome of a private coin toss without

\footnotetext{
${ }^{1}$ For example, recent estimates show that in the U.S., employees are responsible for as much as $\$ 994$ billion of annual losses due to occupational fraud (ACFE, 2008).

2 Interesting work by Hsee $(1995,1996)$ teaches us that people are not inherently honest or dishonest - rather, the level of honesty varies by context. For example, Hsee's work suggests that people cheat in some situations but not in others, and people vary with respect to the context in which they will choose to cheat.
} 
being detected. We predict that increased scrutiny results in less dishonesty. To test this prediction, we vary whether the parent's child is in the room during the coin toss. Further, we propose that the moral cost associated with a dishonest act significantly impacts behavior. To evaluate this prediction, we conduct two additional treatments in which we vary whether the payoff is a prize for the child or for the parent.

The effect of "scrutiny" on honesty may arise both because a parent does not want to look like a dishonest person in front of their child and, relatedly, because parents want to transmit positive attitudes towards honesty to their children. For this reason, our empirical examination of the scrutiny effect provides insights into the development of dishonesty. ${ }^{3}$ We propose that parents may transmit honest behavior because acting dishonestly imposes a moral cost, which is strongest when the child is nearby. Moreover, our analysis enables us to discover empirically whether existence and size of this scrutiny effect depends on whether the child is a son or a daughter.

Whether parents' impulse for dishonest behavior varies under the scrutiny of sons or daughters is an important empirical question. Studies in economics and psychology have shown adult males to be more likely than females to engage in acts of dishonesty (Alm, Jackson and McKee, 2009; Jackson et al., 2002; Ward and Beck, 1990). To study gender differences in the propensity to lie, Dreber and Johannesson (2008) used a sender and receiver game in which the sender has a monetary incentive to send a deceptive message. They found that men lie more than women (55\% vs. 38\%). This result accords well with Houser, Vetter and Winter (2012) who showed that men are more likely than women to incorrectly report the result of a private coin toss.

\footnotetext{
3 Relatedly, scholars have investigated the inter-generational transfer of skills, preferences and attitudes from parents to children. For example, Bisin and Verdier (2001) find paternalistic altruism to underlie parents' transmission of preferences and cultural values to children. Recent data suggest that parents also transmit risk and trust preferences to children (Dohmen et al., 2012).
} 
Field evidence also suggests that men cheat more than women. Data on fare dodging collected in Italy showed that men are more likely to cheat (Bucciol, Landini and Piovesan, 2013). Females were also found to be more likely to return excess change at the restaurant (Ofer, Shira and Bar-Eli, 2013) and had weaker cheating intentions on exams (Tibbetts, 1999). Tibbetts results suggest that women having a stronger tendency to feel shame from actions that deviate from honesty might be an explanation. That research also finds that men display less selfcontrol, leading them to disobey rules more frequently. Fosgaard, Hansen, and Piovesan (2013) manipulated the moral cost of dishonesty and found that women are more honest than men in situations where the moral cost is higher (see also Friesena and Gangadharan, 2012; and Erat and Gneezy, 2012 for related results). Understanding parental modeling to sons and daughters is one way to shed light on the documented gender differences among adults.

In our experiment, we observe the highest level of cheating in the setting with low moral cost and no scrutiny: when the parent is alone and the prize is for the child. Overall, we find that parents are more likely to cheat to benefit their child than to benefit themselves. Thus, the impulse to benefit one's child through dishonest acts seems substantially greater than the impulse to benefit oneself in that same way. Importantly, we find that parents cheat less when their daughter is present, but do not change their behavior in front of sons. That is, the impulse to benefit one's daughter through dishonest acts is extinguished by that same daughter's scrutiny, perhaps due to the parent's desire to model honesty. This finding sheds light on the development of the widely documented gender differences in cheating behavior among adults discussed above. 
The remainder of our study is crafted as follows. Section 2 provides our conjectures and discusses related literature in light of the theory. Section 3 describes the experiment design and procedures. Section 4 summarizes findings. Section 5 concludes.

\section{Background}

\subsection{Related Literature}

Research on dishonesty, deception, lying and cheating spans many fields including psychology (e.g., Hegarty and Sims, 1978; Beck and Ajzen, 1991; Depauloet al., 1996; Monin and Jordan, 2009), neuroscience (e.g., Cazzaniga, 1995; Yang et al., 2005; Harvey et al., 2010) and philosophy (Green, 2004). Within economics, a growing body of literature has found evidence of individual dishonesty when cheating is unobservable (Erat and Gneezy, 2012; Gneezy, 2005; Fischbacher and Föllmi-Heusi, 2013; Abeler et al., 2014; Freeman and Gelberg, 2010; Bucchiol and Piovesan, 2009; Pruckner and Sausgruber, 2008; Cappelen, Sorensen, and Tungodden, 2013; Houser et al., 2012; Hao and Houser, 2013) and in cheap talk games in the laboratory (Sutter, 2009; Charness and Dufwenberg, 2006 Gneezy, 2005; Chen and Houser, 2014). Studies also found that some individuals are inherently honest and are not tempted to engage in cheating behavior (Greene and Paxton, 2009), and some individuals cheat only a little, potentially due to the desire to preserve a favorable self-concept (Mazar et al., 2008). Recent papers in economics also reported that children ages 5-15 behave dishonestly when given the opportunity to do so (Bucciol and Piovesan, 2011) and that they are also willing to act unfairly if they can maintain an appearance of fairness in front of the experimenter (Shaw et al. 2014).

The existing literature also confirms that context is extremely important in determining whether an individual will cheat. For example, Gneezy (2005) found that the consequences of the lie (relevant payoffs) turn out to have an important impact on behavior. Erat and Gneezy (2012) 
found that a non-negligible number of people lie when it benefits another (see also Gino et al., 2013; Gino and Pierce, 2010), a result explained by the fact that individuals view their unethical actions as morally acceptable when others may benefit. Houser et al. (2012) found that when subjects perceive being treated unfairly in one environment, they are more likely to cheat in a subsequent unrelated context. Also, people are more likely to be dishonest after having observed their peers acting dishonestly (Gino et al., 2009). In addition, Mazar et al. (2008) and Vohs and Schooler (2008) reported that dishonesty decreases after moral reminders.

Being observed (what we refer to as 'scrutiny') has been shown to reduce dishonesty. In one study using field data, dishonest employee behavior was decreased at a firm that introduced theft-monitoring technology (Pierce et al., 2014). In a field experiment with tax payers in Norway, Bott et al. (2014) found that increasing the perceived probability of detection increased the amount of foreign tax reported by tax payers. In a laboratory experiment, individuals were more likely to compensate for unethical actions of in-group members when they are observed by an out-group member (Gino et al., 2009). Additionally, Gino et al. (2012) found that feeling psychologically close to someone who has behaved selfishly causes individuals to consider the selfish behavior as less unethical. Finally, in public goods games, individuals contribute more to the group when they are observed in an effort to avoid shame from being a low contributor (Samek and Sheremeta, 2014).

A large literature in developmental psychology has investigated the evolution of lying in very young children (see Talwar and Crossman, 2011, for a review). According to this literature, with age, children learn to lie even as they learn about the social norms that promote honesty. ${ }^{4}$

\footnotetext{
${ }^{4}$ According to Talwar and Crossman (2011), lying behavior development is not linear and instead follows an inverted 'u-shaped' function - children's lie telling may increase from preschool to elementary school years as they learn how to lie, but later decreases through socialization processes of adults and peers.
} 
Children's understanding of 'what is a lie' evolves throughout preschool and elementary school - lie definitions start out rule based (i.e., incorrect statements are always a lie) and become more nuanced as children get older (including the speaker's intentions and the social acceptability of the lie). While very early work (Piaget, 1932/1965) suggested that children cannot differentiate the nuances of a lie, more recent work did find that children as young as 4-7 can evaluate the appropriateness of lies based on intentions and consequences (Bussey, 1999; Heyman et al., 2009).

Evidence suggests that children begin telling lies as early as age 2-4, and the preschool years are a time of rapid development in ability to lie (Newton et al., 2000; Lewis et al., 1989; Talwar and Lee, 2002). Talwar and Lee (2002) found that the majority of 4-7 year olds will lie about peeking at a toy, while $2 / 3$ of 3-year olds will. Pro-social lying, or lying to benefit another or protect his or her feelings, develops somewhat later. In one experiment, $72 \%$ of children ages 3-5 told a white lie, while $80 \%$ of children ages $6-8$ and $84 \%$ of children ages $9-11$ did so (Talwar et al., 2007). Children also respond to parental coaching at a young age, with $68 \%$ of children telling a white lie spontaneously and $87 \%$ of children telling a white lie when their parents ask them to (Talwar et al., 2007). However, lying frequencies decrease significantly among adolescents: Glätzle-Rützler and Lergetporer (2015) find that lying frequencies are lower in $16 / 17$ year-olds relative to $10 / 11$ year-olds.

Interestingly, Hays and Carver (2014) found that children were more likely to lie if they had been previously deceived by an adult. Thus, experiences do seem to matter in children's learning of a lie. However, in Hays and Carver (2014) the effect was concentrated only among school-age children (and there was no effect on preschoolers), suggesting that children become more susceptible to adult modeling as they get older. Thus, children in our age group should be 
able to understand when a parent lies to the experimenter, and may respond to a parent's request not to tell the experimenter about the lie.

Gender differences in the propensity to lie also emerge at an early age. In one paper, mothers and teachers rated lying and disruptive behaviors of girls and boys aged 6-8, finding that girls are rated as lying less than boys (Gervais et al., 2000). Maggian and Villeval (2014) found some gender differences in child lying behavior as well - at ages 7-8, boys are significantly more likely than girls to tell lies that hurt another. Bucciol and Piovesan (2011) found that girls are less willing to lie if a moral reminder is used. In a related paper, we found that girls are more altruistic than boys among children drawn from the same study population as the study reported here (List and Samak, 2013).

\subsection{Predictions}

We provide a simple framework that incorporates moral cost in an individual's decision to behave dishonestly. Our predictions about dishonest behavior closely follow the theory of Levitt and List (2007), who proposed that an action has two channels through which it potentially affects utility: wealth and a non-pecuniary moral cost or benefit. As the stakes increase, the more the action affects wealth. Likewise, actions that might be viewed as immoral or anti-social may impose non-pecuniary costs (see Akerlof and Kranton, 2000; 2005; Gazzaninga, 2005).

As the negative impact on others increases, the moral cost grows larger in absolute value. Individuals also pay a moral cost for violating social norms or legal rules that govern behavior. As Levitt and List (2007) note, "moral concerns depend on the nature and extent of how an 
individual's actions are scrutinized - such as whether the act is in front of one's children." We propose that the effect of scrutiny is to further increase the relevance of moral costs.

In the context of our experimental design, described below, we highlight several relevant predictions. The first prediction relates to the recipient of the payoff from cheating. In our experiment, parents are randomized to either a treatment in which the payoff is a toy for the child or cash for the parent. To address the directional differences we expect, we turn to related literature on self-image. According to Mazar et al. (2008), people do not cheat all the time because they gain utility from a positive self-image and are sensitive to the consequences of a lie. The premise of the theory is that individuals prefer to maintain a positive self-image, but will cheat if they can do so without negatively updating their self-image (Gur and Sackeim, 1979). Similar to the findings of Gino et al. (2013), parents in our study may have a 'license to cheat' when they are alone and when their cheating can benefit another (in this case, their child). While stealing cash is hard to rationalize, stealing a toy for a child may be easier to rationalize (e.g., $I$ decided to cheat because this is what parents do for their child.). In other words, the moral cost of cheating is lower when the prize is for the child than for the parent. This leads us to our first prediction, which is that when the parent is alone, the level of dishonesty should be higher when the prize is for the child than for the parent. Moreover, the level of dishonesty should be highest when the prize is for the child and when the child is not present.

Our second prediction is that the parent will be less likely to act dishonestly when the child is present, both because the level of scrutiny is higher and also because of the higher moral cost associated with dishonesty when one's child is observing the act. Parents play a central role in a child's socialization and moral development, especially at young ages (Cunha and Heckman, 2009; Maccoby, 1992). Related work on preference development predicts that parents will 
transmit preferences and cultural values to children due to paternalistic altruism (Bisin and Verdier, 2001). It may be more difficult for parents to rationalize dishonest behavior if their child is witnessing it, which would lead to lower rates of dishonesty (e.g., If I cheat in front of my child I will feel bad.). To the extent that parents may feel morally obligated to model honest behavior to children, choosing to behave dishonestly when a child is present imposes a higher moral cost. Thus, our second prediction is that parents will be less likely to act dishonestly when their child is in the room.

The model of Levitt and List (2007) does not make any predictions regarding whether dishonesty should be more or less likely in front of sons than daughters. However, related literature on gender differences in dishonesty - showing that men tend to be more dishonest than women and that boys tend to be more dishonest than girls - provides some insights. If parental modeling is one reason for these gender differences among adults, then we predict that parents may exhibit more honest behavior in front of daughters than in front of sons. In addition, if boys are more likely to be dishonest than girls, they may convince their parents to act more dishonestly in this setting.

\section{The Experiment}

\subsection{Experimental Setup}

The experiment was conducted at the Griffin Early Childhood Center (GECC) in Chicago Heights, Illinois. GECC is itself a large-scale field experiment that seeks to understand the impact of early childhood interventions on the academic development of children from lowincome households; as such, GECC is located in Chicago Heights, Illinois, a predominately lowincome and high minority suburb of Chicago (median household income of $\$ 43,102$ with $29 \%$ of

persons below poverty level). The racial composition of Chicago Heights includes a high 
proportion of African-American (41.5\%) and Hispanic (33.9\%) households. ${ }^{5}$ Each summer, parents of children aged 3-4 signed up their children for a lottery, giving them the opportunity to be randomized into a preschool program, to a parenting program or to a control group. In addition to early childhood interventions, GECC is set up to serve as a 'laboratory' for experiments with parents and children (see Appendix A for more detail on the setting).

Each parent-child pair participated only once. The field experiment was conducted in a classroom at the school, and the parent-child pair participated one-on-one with an experimenter (in the parlance of Harrison and List (2004), we conducted an artefactual field experiment). Participation required approximately 15 minutes. Instructions were viewed via a video on the experimenter's computer (see Appendix B for instructions). Because it was important that both the parent and the child comprehend the procedures, both the instructions and the record sheet were created so that they could be understood by both parents and their children. ${ }^{6}$

\subsection{Experimental Design}

The experiment proceeded as follows. While the experimenter was out of the room, parents flipped two coins each with a green and blue side, and reported the outcome of the coin toss on a record sheet. Reporting \{green, green\} resulted in a prize, whereas reporting any other outcome did not result in a prize. Participants flipped each coin only once. We did not invite participants to cheat, though we did clearly indicate that we would not observe the outcome of the coin toss. ${ }^{7}$

We conducted four treatments using a $2 \times 2$ design in which we systematically varied

\footnotetext{
${ }_{6}^{5}$ Data taken from Census.gov Quickfacts, see http://quickfacts.census.gov/qfd/states/17/1714026.html.

${ }^{6}$ For instance, the instruction format was interactive and included several comprehension questions. The authors have experience in designing these sorts of experiments for young children, and used their expertise when designing this experiment.

${ }^{7}$ Related cheating experiments using dice or coins are reported by Fischbacher and Föllmi-Heusi (2013); Bucciol and Piovesan (2008), Houser et al. (2012) and Fosgaard et al. (2013).
} 
whether the child was in the room during the coin toss, and whether the reward was for the parent or for the child (see Table 1). Parent-child pairs were randomly selected into one of the four treatments. In all treatments, the child was in the room with the parent while the instructions were read. In treatments where the parent flipped the coin alone ( $\mathrm{Pa} \_\mathrm{P}$ and $\left.\mathrm{Pa} \_\mathrm{C}\right)$, the child was asked to leave the room with the experimenter during the coin toss; whereas in treatments where the parent flipped the coin with the child (PC_P and PC_C), the child was asked to remain in the room with the parent. In treatments where the child remained in the room with the parent (PC_P and $\mathrm{PC} \_$C), children and parents could communicate with one another, but were instructed that the coin flip and recording was up to the parent, and not the child. ${ }^{8}$

To assure that the child would pay attention to the outcome of the coin toss in PC_P and PC_C, we incorporated child involvement in a natural way by instructing the child to play a card matching game during the experiment. ${ }^{9}$ In treatments where the child left the room with the experimenter, the experimenter played the same coin toss and card matching game in the hall with the child - however, as in the other treatments, the parent and child were instructed that it is the adult's coin toss outcome that 'counted' for winning the prize.

\section{[ TABLE 1 ABOUT HERE ]}

Prizes were shown to the participants prior to the coin toss. In the treatment where the prize was for the parent ( $\mathrm{PC} \_\mathrm{P}$ and $\left.\mathrm{Pa} \_\mathrm{P}\right)$, the parent received $\$ 10$ wrapped with a bow if the reported outcome was \{green, green\} and nothing otherwise. In the treatment where the prize was for the child (PC_C and $\mathrm{Pa} \_\mathrm{C}$ ), the child could choose between several different genderneutral prize packs if the reported outcome was \{green, green $\}$, and nothing otherwise. The prize

\footnotetext{
${ }^{8}$ We did not record the communications since the decision was made in private.

${ }^{9}$ In the card matching game, the child was given 2 blue and 2 green cards. The child was told to watch for the outcome of the coin toss, and then hold up the cards corresponding to the outcome (e.g., 2 blue cards for both coins blue side up, and so on). Then the child was asked to put the cards away and wait for the experimenter to return in order to give the outcome sheet to him/her.
} 
pack consisted of a 5" stuffed zoo animal toy (choice of bear, zebra, giraffe, or lion), a colorful pencil, and other small trinkets, so that the approximate price of each prize pack was also around $\$ 10$. At the end of the session, all parents also received the pre-announced \$10 show-up fee.

\section{Results}

\subsection{Sample Description}

A total of 249 parent-child pairs were recruited and participated in the experiment, with children ranging in age from 3 to 6 , with an average of 4.04 (s.e. $=0.04$ ). Most parents in the study were mothers because they were the most likely to bring their child in for the experiment ( $90 \%$ were mothers while $10 \%$ were fathers). Since fathers make up a very small and highly selected sample in our population, we do not analyze differences in cheating across the two groups. Therefore, we pool the mothers and fathers when analyzing the data. 124 of the children were girls, and 125 were boys. Table 2 provides summary statistics of participants by treatment. Since parent-child pairs were randomized to treatment, we do not expect differences in demographics by treatment. Statistical tests comparing demographics by treatment do not show significant differences, except child age between the $\mathrm{PC} \_\mathrm{C}$ and $\mathrm{Pa} \_\mathrm{C}$ treatments is marginally significant ( $p$-values for t-test and Wilcoxon-Mann-Whitney test both $<0.10$ ). In what follows, we provide analysis with and without demographic controls.

\section{[ TABLE 2 ABOUT HERE ]}

\subsection{Testing Our Predictions}

Following other studies in this literature, we do not observe cheating directly. Instead, we 
compare the rate of reported wins to the expected rate to infer whether cheating occurred. ${ }^{10}$ While the objective probability of winning the prize is 0.25 , we find winning rates of 0.39 on average. Winning rates of mothers are 0.39 , while winning rates of fathers are 0.35 . A reported rate of winning that is different from the expected rate suggests that participants are providing dishonest reports for private benefit.

First, we explore the underlying pattern of cheating rates in the $2 \times 2$ experiment. As reported in Table 3, rates of winning are strongly influenced by context. Win rates of $0.35,0.36$ and 0.33 in treatments $\mathrm{PC}_{-} \mathrm{C}_{2} \mathrm{PC}_{-} \mathrm{P}$ and $\mathrm{Pa} \mathrm{P}_{-}$are all higher than 0.25 , though not significantly individually (t-test $p$-values $>0.10$ comparing each treatment to 0.25 , except PC_P with $p$-value $=0.08)$. When pooled, however, the differences are significant ( $p$-value $<0.01)$.

We turn to our first prediction, that cheating is greater when the reward is for the child than for the parent. When the parent is alone, we see statistically significantly higher winning rates when the prize is for the child $\left(0.50\right.$ in $\left.\mathrm{Pa} \_\mathrm{C}\right)$ than when they are for the parent $(0.33$ in Pa_P $)$, confirming our prediction $\left(\mathrm{Chi}^{\wedge} 2 p\right.$-value $\left.=0.05\right)$. When the parent is with the child, we do not observe significant differences in cheating depending on the recipient of the prize, and one possible reason is that the child's presence interacts with the moral cost associated with cheating for the child or parent (winning rates are 0.35 in $\mathrm{PC}_{-} \mathrm{C}$ and 0.36 in $\mathrm{PC}$ - , not a significant difference). Pooling treatments with and without child presence, we observe winning rates of 0.34 and 0.42 , when the prize is for the parent and child, respectively. This roughly $20 \%$ increase in win rates when the prize is for the child is also consistent with our cheating prediction (though the difference is not statistically significant at conventional levels; note that we make the

\footnotetext{
${ }^{10}$ Houser et al. (2012) show that observed outcome frequencies can be used to infer cheating rates in simple coinflip games under the assumption that subjects do not cheat to their disadvantage. Because estimated cheating rates and observed winning rates are monotonically related, our analysis here focuses exclusively on the latter.
} 
assumption that winning is congruent to cheating). This brings us to the first result:

Result 1: When the parent is alone, the winning (cheating) rate is higher when the prize is for the child than when it is for the parent.

\section{[ TABLE 3 ABOUT HERE ]}

The second part of our first prediction was that the greatest cheating would be observed in Pa_C (parent alone and the prize is for child), since this is the treatment with the lowest moral cost. This is in fact what we observe: in $\mathrm{Pa} \_\mathrm{C}$, the winning rates are at 0.50 , while in the other three treatments winning rates are only 0.35 on average, a statistically significant difference $\left(\mathrm{Chi}^{\wedge} 2 p\right.$-value $\left.=0.03\right)$. Pa_C has statistically significantly higher winning rates than $\mathrm{Pa} \_\mathrm{P}$ $\left(\mathrm{Chi}^{\wedge} 2 p\right.$-value $\left.=0.05\right)$ and marginally significantly higher winning rates than $\mathrm{PC} \_\mathrm{C}\left(\mathrm{Chi}^{\wedge} 2 p\right.$ value $=0.08)$. Indeed, $\mathrm{Pa}_{-} \mathrm{C}$ also has higher winning rates than $\mathrm{PC}$ _ , though the result is not statistically significant $\left(\mathrm{Chi}^{\wedge} 2 \mathrm{p}\right.$-value $\left.=0.13\right)$. This brings us to our second result:

Result 2: The highest winning (cheating) rate is observed in the condition with lowest moral cost: when the parent is alone and the prize is for the child.

Next, we consider our second prediction, that the presence of the child decreases the likelihood of cheating. The rates of winning when a parent is alone are 0.42 , while rates when the parent's child is present are 0.35 (pooling the parent and child prize treatments, respectively). This suggests that parents cheat less in the presence of a child. However, the difference is not statistically significant $\left(\mathrm{Chi}^{\wedge} 2 \mathrm{p}\right.$-value $\left.=0.32\right)$. 
The Logit regression reported in Table 4 provides additional evidence for Results 1 and 2. Here, the dependent variable is reporting a win ( $=1$ for win and 0 otherwise), dummies and interactions are included for the treatments (the omitted treatment is $\mathrm{Pa} \_\mathrm{P}$ ), and we include fixed effects for research assistants ( 8 different research assistants carried out the study one-on-one with the parent/child pair). In the simplest specification (Column 1), we observe higher rates of cheating when the prize is for the child, Prize for Child Dummy (coefficient of 0.71, p-value < 0.10). We also observe a negative coefficient for the Interaction term, when the child is in the room and the prize is for the child (coefficient of $-0.91, p$-value $<0.10$ ). The Child Present Dummy coefficient is positive, but small and insignificant. Similar results are obtained in the second specification (Column 2), which controls for child age. ${ }^{11}$

Recall that the GECC program randomizes families to one of several educational treatments or a control group. One possible reason why parents may cheat more to benefit their child could be that a social norm to help children exists within the GECC context, which is stronger than in other environments. However, we don't believe this is the case for two reasons. First, helping the child in the context of GECC would include providing education at school or at home, rather than providing a non-educational toy, as is the case in our PC_C and $\mathrm{Pa} \_\mathrm{C}$ treatments. Second, if the social norm to help one's child is driven by the GECC context, we may see that parents randomized to the treatment group are more likely to report winning than those who are randomized to the control group. However, when the prize is for the child, we see similar reported winning rates across the groups ( 0.42 reported win rate in the control group, versus 0.425 reported win rate in the treatment group), and coefficients on the GECC Control Group dummy in the regressions in Table 4 are also not significant. Thus, we propose that

\footnotetext{
${ }^{11}$ Table 4 is reproduced without experimenter fixed effects in Appendix C as Table 1A; results are qualitatively similar for all specifications.
} 
Results 1 and 2 are not specific to the GECC program context. Of course, future work that explores the generalizability of our results to other contexts would be welcome.

\section{[ TABLE 4 ABOUT HERE ]}

In summary, we find support for our first prediction that cheating is higher when the prize is for the child than the parent and the parent is alone (Results 1 and 2). However, we do not find strong support for the second prediction, that the presence of the child decreases cheating rates. Therefore, we turn next to the mediators that may affect willingness to cheat in the child's presence. Specifically, in the next sub-section we consider the impact of child's gender.

\subsection{Gender Differences}

Gender differences are observed among adults in related experiments, with men cheating more than women in many studies (Dreber and Johannesson, 2008; Friesena and Gangadharan, 2012; Ward and Beck, 1990). While we did not directly predict any differences in dishonesty by gender, our experiment allows us to answer questions about one channel that impacts the origins of dishonesty by considering whether sons or daughters receive differential treatment from parents in the game.

Aggregating data for both prizes, Figure 1 provides an overview of the reported win rates when the child is a girl or a boy, according to whether the child is with the parent or not. The gender of the child does not matter when the parent is alone, as parents report slightly but not significantly higher win rates for girls $(0.44)$ as compared to boys $(0.40)\left(\mathrm{Chi}^{\wedge} 2 p\right.$-value $\left.>0.10\right)$. However, we do observe significant differences when the child is in the room. As compared to when a son is in the room, in the presence of a daughter, parents are significantly less likely to report a winning outcome $\left(\mathrm{Chi}^{\wedge} 2 p\right.$-value $\left.=0.06\right)$. The rate of reported wins when a daughter is 
with the parent is 0.27 (insignificantly different from expected win rate of 0.25 ), while the reported rate of wins under the scrutiny of a son is 0.44 (statistically significantly different from the expected win rate of 0.25 , t-test $p$-value $<0.01$ ). This brings us to the final result:

Result 3: Parents win (cheat) more often in the presence of sons than daughters.

\section{[ FIGURE 1 ABOUT HERE ]}

Regressions in Table 4 confirm Result 3. The specifications in Columns 3-6 incorporate the gender of the child and treatment-gender interactions, finding a consistently negative and significant coefficient on Child Present*Female (coefficient ranges from -1.46 to -1.67, significance at the $10 \%$ and $5 \%$ levels across the specifications). The specifications in Columns 4-6 also include dummies for whether the child is with his/her mother in the experiment (Mother), and an interaction term for a mother who is with her daughter (Mother*Daughter), but no statistically significant results are found (possibly due to small sample sizes of fathers). We also observe a significant negative coefficient on Prize*Age (coefficient of -1.04 , significant at the $10 \%$ level), suggesting that parents are more willing to cheat for younger children. We do not see any significant effect of older or younger children being present during the experiment (Child Present*Age or Interaction*Age), however.

We interpret our results as indicative of the fact that parents are more likely to model honest behavior in front of sons than daughters, which is a possible driver of the gender differences observed among adults. This would explain why cheating rates are lower when daughters are present as compared to sons, yet cheating rates are similar for parents of daughters and sons when their child is absent. Through the lens of our predictions that incorporate moral 
cost, this behavior is indicative of the fact that the moral cost of cheating in front of daughters is higher than the moral cost of cheating in front of sons.

The different modeling behavior of parents towards sons as compared to daughters could be consistent with several alternative explanations. While our data do not allow us to formally test these explanations, we attempt to evaluate them vis-à-vis some additional explanations below. For instance, there may be an innate reason to model honest behavior to daughters but not sons. In addition, if parents are aware of the social norm that adult women are more honest than adult men, then this kind of modeling could be driven by a desire to disproportionately teach honesty norms to daughters.

The second alternative explanation is that girls may understand the task better than boys, which would mean that parents would incur a higher moral cost lying in front of girls than in front of boys, in line with our predictions. While $95 \%$ of parents reported that the child did the card task correctly, there may still be some differences in understanding. To proxy for understanding the task, we use the child's summer 2011 reading, writing and math achievement score, which is an average of four sub-tests of the Woodcock Johnson III Test of Achievement and the Peabody Picture Vocabulary Test, normed for age. ${ }^{12}$ We observe cognitive percentile scores of $41.8 \%$ (s.e. $=2.1 \%$ ) for girls, and $36.1 \%$ for boys $($ s.e. $=1.79 \%$ ), which may suggest that girls were more likely to understand the task, and therefore parents were less willing to lie in front of them.

12 The Woodcock-Johnson III Test of Achievement is produced by Riverside Publishing (see http:/www.riverpub.com/products/wjIIIComplete/). We utilize the following four sub-tests: Letter-Word, Spelling, Applied Problems, and Quantitative Concepts. The Peabody Picture Vocabulary Test is produced by Pearson and measures receptive vocabulary (see http://www.pearsonclinical.com/language/products/100000081/peabody-picturevocabulary-test-third-edition-ppvt-iii.html). Both tests are age-normed. GECC children are assessed at the beginning of each year during a one-on-one assessment with a trained assessor. 
Third, girls may be more likely to tell the parent's 'secret' to the experimenter. If parents think their cheating may be exposed to the experimenter, this increases scrutiny and we predict decreased cheating rates. In the post-experiment survey, we asked parents, "if someone told your child a secret, how likely would he/she be to tell someone else?" on a 5 point scale (where 1 is 'would definitely tell', and 5 is 'would definitely not tell.') The average response was 2.40 (s.e. $=0.09$ ) for girls and 2.25 (s.e. $=0.08$ ) for boys, and the difference was not statistically significant (Wilcoxon-Mann-Whitney $p$-value $=0.2$, t-test $p$-value $=0.17$ ). Thus, girls were rated as slightly less likely to tell a secret than boys, suggesting that the possibility for further scrutiny may not be driving the differences in parental modeling for sons versus daughters. ${ }^{13}$

The fourth alternative explanation is that girls innately may be more inclined to follow rules or may be more conscientious, and therefore may be more upset if parents lied in front of them. For instance, related work shows that while boys and girls are equally pro-social, competitive environments crowd out the pro-sociality of boys but not girls (Houser and Schunk, 2009). If children viewed the environment as a competition, this may have led boys, but not girls, to behave selfishly and cheat the experimenter. Again, upsetting a child would incur a higher moral cost, in line with our predictions. In a separate survey with the GECC population, we also collected "Big 5" survey measures on the children (parents were the respondents) and can use a measure of child "conscientiousness" as an additional control (97\% of participants responded to the "Big 5" survey). The conscientiousness score was 0.77 (s.e. $=0.02$ ) for daughters and 0.75 $(\mathrm{s} . \mathrm{e} .=0.02)$ for sons (no statistically significant differences, t-test $p$-value $=0.38$ ). Thus,

\footnotetext{
${ }^{13}$ Interestingly, many parents said their child "would definitely tell" (18\%) or "would probably tell" (37\%), yet we did not observe children telling on parents for cheating at any time in the experiment. This could be because we did not request children to tell, and the experiment always ended with children picking out a participation prize, so they may have been distracted by their new toy.
} 
conscientiousness may not play a large role in explaining gender differences in parental modeling.

Table 5 provides Logit regressions with win response as the dependent variable, in which we incorporate each of the above control variables and their interactions with treatment and gender to confirm the possible explanations below. The first specification (Column 1) provides a control for child's cognitive score (Cognitive Score) and interactions with treatments (Child Present*Cog, Prize for Child*Cog, Interaction*Cog) and with gender (Child Present ${ }^{*}$ Female ${ }^{*}$ Cog, Prize for Child ${ }^{*}$ Female ${ }^{*}$ Cog, Interaction $*$ Female ${ }^{*}$ Cog). The coefficient on Child Present*Female remains negative and significant at the $10 \%$ level $(-2.95, p$ value $<0.10$ ); moreover, the coefficients on Cog, Child Present ${ }^{*} \operatorname{Cog}$ and Child Present $^{*}$ Female ${ }^{*} \operatorname{Cog}$ are small and insignificant. This suggests that while we do observe differences in cognitive scores by gender, these differences do not fully explain our results.

Specification 2 (Column 2) reports on controls and interactions for Secret (whether the child would tell a secret). In this specification, the Child Present*Female coefficient is still similar in magnitude (-2.02) but no longer statistically significant, meaning that the willingness to tell a secret (or scrutiny) may drive the results at least partially. Finally, specification 3 (Column 3) reports on controls and interactions for Conscientious (the child's conscientiousness score on the Big Five survey for parents, where 0 is least and 1 is most conscientious). Here, we find that conscientiousness mediates the effect - girls who are more conscientious tend to have parents who lie less - but the result is not statistically significant (coefficient $=-3.84, p$ value $>0.10)$.

Note also that the majority of parents in the experiment were mothers, which is unsurprising considering that we did not specify which parent should attend, and many studies 
find that mothers spend more time with their children than fathers (e.g., Craig, 2006). One may speculate that perhaps mothers care more about rearing their daughters than sons, which may affect our results; however, a meta-study surveying differences between mother-daughter, fatherdaughter, mother-son and father-son relationships did not find broad empirical support for such speculation (Russell and Saebel, 1997). Some studies do find gender differences for child investment. Thomas (1994) uses household survey data and finds that mother's education has a bigger effect on her daughter's height, while father's education had a bigger effect on his son's height, suggesting a difference in how household resources are allocated.

\section{[ TABLE 5 ABOUT HERE ]}

\subsection{Elasticity of Honesty}

Our data also provide an opportunity to investigate the price elasticity of honesty. Assuming that honesty is a normal good, sharing standard features of private goods, as the price (pecuniary or non-pecuniary) of honesty increases, the quantity of honesty demanded should decrease. The elasticity of honest behavior can therefore be calculated by measuring how responsive honest acts are to changes in the stakes. For example, when using the results of Fischbacher and Follmi-Heusi (2013) and the treatment group sub-sample (since levels vary from treatment to control), a back of the envelope calculation yields price elasticities of -0.38 and -0.69 . In Gneezy (2005), two elasticities also emerge from the empirical results, -0.17 and $-0.33 .^{14}$ These figures

\footnotetext{
${ }^{14}$ In Fischbacher and Follmi-Heusi (2013), subjects roll a die and then self-report the number. They are paid the number they report, unless they report six in which case they earn zero. Thus, if there are no costs to lying and people are earnings maximizers, everyone should report 5 . The price of an honest report $\mathrm{X}$ is the difference between what they could have earned by lying (5) and their report $X$, unless $X=6$ in which case the price is 5 . Using the percent of subjects who received each payout (0-5), we computed quantity of each report as a function of price using Matlab's polyfit function for the first and second degree polynomial. Letting Qn be the n degree polynomial, we have: $\mathrm{Q} 1=-5.82 \mathrm{P}+31.23$ and $\mathrm{Q} 2=1.35^{\wedge} 2-12.59 \mathrm{P}+35.74$. To evaluate the elasticity, we assumed the weighted average
} 
point to our conclusion that the demand for honesty is relatively inelastic. This is interesting because one could now conclude that the contextual estimates that we find, and the broader literature finds, show the importance of context in determining how honesty responds to price.

\section{Discussion \& Conclusion}

When humans are given the chance to behave dishonestly (e.g. they have the opportunity to cheat to their own advantage), Becker (1968) predicted their behavior would be determined by the marginal pecuniary costs and marginal pecuniary benefits of their actions. In fact, the decision to act dishonestly seems to be influenced by a much richer set of variables. Further, related literature suggests that individuals trade-off between the pecuniary value of dishonest acts and the moral and self-image costs that can result from cheating.

We proposed that incorporating moral costs and scrutiny can shed light on the underlying channels through which context may influence decisions to behave dishonestly. Our central prediction is that a higher moral cost results in a lower rate of dishonesty. We tested this prediction using a field experiment with parent-child pairs to investigate the willingness of parents to lie about the outcome of a coin toss when 1) the child is present or absent and 2) when the benefit of the lie is to the parent or to the child.

Consistent with a broad literature, we find that cheating rates are significantly affected by context. Specifically, our data points to several major conclusions. First, when the parent is alone, the winning (cheating) rate is higher when the prize is for the child than when it is for the parent. Second, the highest winning (cheating) rate is observed in the condition with the lowest

$(\mathrm{Pavg}=1.48)$ and the corresponding quantities are $\mathrm{Q} 1=22.6$ and $\mathrm{Q} 2=20.06$. Thus, $\mathrm{E} 1=-0.38$ and $\mathrm{E} 2=-0.69$. In Gneezy (2005) one can calculate similarly, and discover elasticity values of -0.17 and -0.33 . 
moral cost: when the parent is alone and the prize is for the child. In this way, our results provide evidence for the importance of moral costs in settings where dishonesty is possible.

In addition to shedding light on the moral costs, our paper also provides some evidence on the transmission of honesty (and dishonesty) in society, connecting to the literature on intergenerational transfer of preferences. For example, we find that the child's gender matters: parents are significantly more likely to win (cheat) in the presence of their son than their daughter. Thus, while some parents may choose to act dishonestly in private, they also seem aware of the benefits of modeling honest behavior to their children.

Our result on inter-generational transmission may provide insights into one channel driving gender differences in dishonesty observed amongst adults. We show that parents model honest behavior more to daughters than to sons, opening up the possibility that gender differences in cheating rates among adults could be driven by differences in the way girls and boys are socialized by parents at early ages. Indeed, the channel to how this might operate has empirical support in the literature: the findings of Hayes and Carver (2014) show that children who are exposed to lying adults are more likely to lie themselves. Combining this with the findings of our paper, one might speculate that adult males are found to lie more often than adult females because, in part, parents constrain their lying behavior to a greater degree under the scrutiny of daughters than sons. Of course, the chain of logic might have a certain degree of circularity, as our experimental subjects might show these sorts of gender effects because they have observed disparities amongst adults in their daily lives. In this way, it is possible that they have greater moral obligation to be honest in front of their daughters than in front of their sons.

Finally, this research also contributes to our general understanding of how cheating to help another may differ from cheating to help oneself. In line with Gino et al. (2013), parents in 
our study were more likely to lie to benefit their child than to benefit themselves. In fact, a recent paper that investigates the transmission of lying behavior among socially connected individuals finds that an individual's lying tendencies can be predicted by the lying tendencies of his or her friends and family members (Mann et al., 2014).

Our research was conducted using a particular field setting - mostly low-income mothers from the Griffin Early Childhood Center in Chicago Heights, Illinois. Our results on parental modeling have the strongest interpretation when concerning mothers, since the number of fathers in our sample was small. Future work should investigate the generalizability of our results by conducting replication experiments with parents and children from diverse other populations, with a special emphasis on recruiting fathers, for whom we have sparse data.

\section{References}

Abeler, Johannes, Anke Becker, and Armin Falk. "Representative Evidence on Lying Costs." Journal of Public Economics, 2014. doi:10.1016/j.jpubeco.2014.01.005.

Akerlof, George A., and Rachel E. Kranton. "Economics and Identity." Quarterly Journal of Economics 115, no. 3 (2000): 715-53. doi:10.1162/003355300554881.

Akerlof, George A., and Rachel E. Kranton. "Identity and the Economics of Organizations." Journal of Economic Perspectives 19, no. 1 (2005): 9-32. doi:10.1257/0895330053147930.

Alm, James, Betty R. Jackson, and Michael Mckee. "Getting the Word Out: Enforcement Information Dissemination and Compliance Behavior." Journal of Public Economics 93, no. 3-4 (2009): 392-402. doi:10.1016/j.jpubeco.2008.10.007.

Ariely, Dan. The (Honest) Truth About Dishonesty: How We Lie to Everyone-- Especially Ourselves. UK: HarperCollins, 2012.

Arrow, Kenneth J. "Gifts and Exchanges," Philosophy \& Public Affairs, Vol. 1, No. 4 (Summer, 1972), pp. 343-362. 
Azar, Ofer H., Shira Yosef, and Michael Bar-Eli. "Do Customers Return Excessive Change in a Restaurant?" Journal of Economic Behavior \& Organization 93 (2013): 219-26. doi:10.1016/j.jebo.2013.03.031.

Beck, Lisa, and Icek Ajzen. "Predicting Dishonest Actions Using the Theory of Planned Behavior." Journal of Research in Personality 25, no. 3 (1991): 285-301. doi:10.1016/0092-6566(91)90021-H.

Becker, Gary S. "Crime and Punishment: An Economic Approach." Journal of Political Economy 76, no. 2 (1968): 169. doi:10.1086/259394.

Bisin, Alberto, and Thierry Verdier. "The Economics of Cultural Transmission and the Dynamics of Preferences." Journal of Economic Theory 97, no. 2 (2001): 298-319. doi:10.1006/jeth.2000.2678.

Bott, Kristina, Alexander W. Cappelen, Erik Ø. Sørensen, and Bertil Tungodden. "You’ve got mail: A randomised field experiment on tax evasion."NHH Norwegian School of Economics (2014).

Bucciol, Alessandro, and Marco Piovesan. "Luck or Cheating? A Field Experiment on Honesty with Children." Journal of Economic Psychology32, no. 1 (2011): 73-78. doi:10.1016/j.joep.2010.12.001.

Bucciol, Alessandro, Fabio Landini, and Marco Piovesan. "Unethical Behavior in the Field: Demographic Characteristics and Beliefs of the Cheater." Journal of Economic Behavior \& Organization 93 (2013): 248-57. doi:10.1016/j.jebo.2013.03.018.

Bussey, K. (1992). Lying and truthfulness: Children's definitions, standards, and evaluative reactions. Child Development, 63, 129-137.

Cappelen, Alexander W., Erik Ø. Sørensen, and Bertil Tungodden. "When Do We Lie?" Journal of Economic Behavior \& Organization 93 (2013): 258-65. doi:10.1016/j.jebo.2013.03.037.

Cazzaniga, Michael S. "Consciousness and the Cerebral Hemispheres." In The Cognitive Neurosciences. Mit Press, 1995.

Charness, Gary, and Martin Dufwenberg. "Promises and Partnership." Econometrica 74, no. 6 (2006): 1579-601. doi:10.1111/j.1468-0262.2006.00719.x.

Chen, Jingnan, and Daniel Houser. "Promises and Lies: An Experiment on Detecting Deception." ICES Working Paper, No 1038, 2013. 
Craig, Lyn. "Does Father Care Mean Fathers Share? A Comparison of How Mothers and Fathers in Intact Families Spend Time with Children." Gender and Society. 2006. Volume 20, no. 2, pages 259-281.

Cunha, Flavio, and James J. Heckman. "Investing in Our Young People." Rivista Internazionale Di Scienze Sociali 117, no. 3 (2009): 387-418. doi:10.3386/w16201.

Depaulo, Bella M., Deborah A. Kashy, Susan E. Kirkendol, Melissa M. Wyer, and Jennifer A. Epstein. "Lying in Everyday Life." Journal of Personality and Social Psychology 70, no. 5 (1996): 979-95. doi:10.1037//0022-3514.70.5.979.

Dreber, Anna, and Magnus Johannesson. "Gender Differences in Deception." Economics Letters 99, no. 1 (2008): 197-99. doi:10.1016/j.econlet.2007.06.027.

Erat, Sanjiv, and Uri Gneezy. "White Lies." Management Science 58, no. 4 (2012): 723-33. doi:10.1287/mnsc.1110.1449.

Fischbacher, Urs, and Franziska Föllmi-Heusi. "Lies In Disguise-An Experimental Study On Cheating." Journal of the European Economic Association 11, no. 3 (2013): 525-47. doi:10.1111/jeea.12014.

Fosgaard, Toke Reinholt, Lars Gaarn Hansen, and Marco Piovesan. "Separating Will from Grace: An Experiment on Conformity and Awareness in Cheating." Journal of Economic Behavior \& Organization 93 (2013): 279-84. doi:10.1016/j.jebo.2013.03.027.

Friesen, Lana, and Lata Gangadharan. "Individual Level Evidence of Dishonesty and the Gender Effect." Economics Letters 117, no. 3 (2012): 624-26. doi:10.1016/j.econlet.2012.08.005.

Gervais, Jean, et al. "Children's persistent lying, gender differences, and disruptive behaviours: A longitudinal perspective." International Journal of Behavioral Development 24.2 (2000): 213-221.

Gino, Francesca, and Adam D. Galinsky. "Vicarious dishonesty: When psychological closeness creates distance from one's moral compass."Organizational Behavior and Human Decision Processes 119.1 (2012): 15-26.

Gino, Francesca, Jun Gu, and Chen-Bo Zhong. "Contagion or restitution? When bad apples can motivate ethical behavior." Journal of Experimental Social Psychology 45.6 (2009): 12991302.

Gino, Francesca, and Lamar Pierce. "Dishonesty in the Name of Equity." Psychological Science 20, no. 9 (2009): 1153-160. doi:10.1111/j.1467-9280.2009.02421.x. 
Gino, Francesca, and Lamar Pierce. "Lying to Level the Playing Field: Why People May Dishonestly Help or Hurt Others to Create Equity." Journal of Business Ethics 95, no. S1 (2010): 89-103. doi:10.1007/s10551-011-0792-2.

Gino, Francesca, Erin L. Krupka, and Roberto A. Weber. "License to Cheat: Voluntary Regulation and Ethical Behavior." Management Science 59, no. 10 (2013): 2187-203. doi:10.1287/mnsc.1120.1699.

Gino, Francesca, Shahar Ayal, and Dan Ariely. "Self-serving Altruism? The Lure of Unethical Actions That Benefit Others." Journal of Economic Behavior \& Organization 93 (2013): 285-92. doi:10.1016/j.jebo.2013.04.005.

Glätzle-Rützler, Daniela and Lergetporer, Philipp. (2015). "Lying and age: An experimental study.” Journal of Economic Psychology, Vol. 46, pages 12-25.

Gneezy, Uri. "Deception: The Role of Consequences." American Economic Review 95, no. 1 (2005): 384-94. doi:10.1257/0002828053828662.

Green, Stuart P. "Cheating." Law and Philosophy 23, no. 2 (March 2004): 137-85. http://www.jstor.org/stable/4150568.

Greene, J. D., and J. M. Paxton. "Patterns of Neural Activity Associated with Honest and Dishonest Moral Decisions." Proceedings of the National Academy of Sciences 106, no. 30 (2009): 12506-2511. doi:10.1073/pnas.0900152106.

Gur, Ruben C., and Harold A. Sackeim. "Self-deception: A Concept in Search of a Phenomenon." Journal of Personality and Social Psychology 37, no. 2 (1979): 147-69. doi:10.1037//0022-3514.37.2.147.

Hao, Li, and Daniel Houser. "Perceptions, Intentions, and Cheating." ICES Working Paper, No 1039, 2013.

Harrison, Glenn W., and John A. List. "Field Experiments." Journal of Economic Literature 42, no. 4 (2004): 1009-055. doi:10.1257/0022051043004577.

Harvey, Ann H., Ulrich Kirk, and George H. Denfield. "Monetary Favors and Their Influence on Neural Responses and Revealed Preferences." The Journal of Neuroscience 30, no. 28 (July 14, 2010): 9597-602. doi:http://dx.doi.org/10.1523/JNEUROSCI.1086-10.2010.

Hays, Chelsea, and Leslie J. Carver. "Follow the Liar: The Effects of Adult Lies on Children's Honesty." Developmental Science 17, no. 6 (2014): 977-83. doi:10.1111/desc.12171. 
Hegarty, W. Harvey, and Henry P. Sims. "Some Determinants of Unethical Decision Behavior: An Experiment." Journal of Applied Psychology63, no. 4 (1978): 451-57. doi:10.1037//0021-9010.63.4.451.

Heyman, G. D., Sweet, M. A., \& Lee, K. (2009). Children's reasoning about lie-telling and truthtelling in politeness contexts. Social Development, 18, 728-746.

Houser, Daniel, and Daniel Schunk. "Social environments with competitive pressure: Gender effects in the decisions of German schoolchildren." Journal of Economic Psychology 30, no. 4 (2009): 634-641.

Houser, Daniel, Stefan Vetter, and Joachim Winter. "Fairness and Cheating." European Economic Review 56, no. 8 (2012): 1645-655. doi:10.1016/j.euroecorev.2012.08.001.

Jackson, Chris J., Stephen Z. Levine, Adrian Furnham, and Nicole Burr. "Predictors of Cheating Behavior at a University: A Lesson From the Psychology of Work." Journal of Applied Social Psychology 32, no. 5 (2002): 1031-046. doi:10.1111/j.1559-1816.2002.tb00254.x.

Jordan, Alexander H. "The Dynamic Moral Self: A Social Psychological Perspective." In Moral Self, Identity and Character: Prospects for a New Field of Study, by Benoît Monin. Cambridge University Press, 2009.

Levitt, Stevin D., and John A. List. "What Do Laboratory Experiments Measuring Social Preferences Reveal About the Real World." Journal of Economic Perspectives 21, no. 2 (2007): 157-74. doi:10.1257/jep.21.2.153.

Lewis, M., Stanger, C., \& Sullivan, M. W. (1989). Deception in 3-year-olds. Developmental Psychology, 25, 439-443.

List, John A., and Anya C. Samak. "Exploring the origins of charitable acts: Evidence from an artefactual field experiment with young children." Economics Letters 118.3 (2013): 431434.

Maccoby, Eleanor E. "The Role of Parents in the Socialization of Children: An Historical Overview." Developmental Psychology 28, no. 6 (1992): 1006-017. doi:10.1037/00121649.28.6.1006.

Maggian, Valeria, and Marie Claire Villeval. "Social preferences and lying aversion in children." Available at SSRN 2368098 (2014). 
Mann, Heather, Ximena Garcia-Rada, Daniel Houser, and Dan Ariely. "Everybody Else Is Doing It; Exploring Social Transmission of Lying Behavior." PLOS ONE, 2014. doi:10.1371/journal.pone.0109591.

Mazar, Nina, On Amir, and Dan Ariely. "The Dishonesty of Honest People: A Theory of SelfConcept Maintenance." Journal of Marketing Research 45, no. 6 (2008): 633-44. doi:10.1509/jmkr.45.6.633.

Newton, P., Reddy, V., \& Bull, R. (2000). Children's everyday deception and performance on false-belief tasks. British Journal of Developmental Psychology, 18, 297-317.

Piaget, J. (1932/1965). The moral judgment of the child. New York: Free Press.

Pierce, Lamar, Daniel C. Snow, and Andrew McAfee. "Cleaning house: The impact of information technology monitoring on employee theft and productivity." (2014).

Russell, Alan and Saebel, Judith. "Mother-Son, Mother-Daughter, Father-Son, and FatherDaughter: Are They Distinct Relationships?” Developmental Review (1997). Vol 17(2), page 111-147.

Shaw, Alex, Natalia Montinari, Marco Piovesan, Kristina R. Olson, Francesca Gino, and Michael I. Norton. "Children Develop a Veil of Fairness." Journal of Experimental Psychology: General143, no. 1 (2014): 363-75. doi:10.1037/a0031247.

Sutter, Matthias. "Deception Through Telling the Truth?! Experimental Evidence From Individuals and Teams." The Economic Journal 119, no. 534 (2009): 47-60. doi:10.1111/j.1468-0297.2008.02205.x.

Talwar, Victoria, and Angela Crossman. "From little white lies to filthy liars: The evolution of honesty and deception in young children." Advances in Child Development and Behaviour 40 (2011): 140.

Talwar, Victoria, and Kang Lee. "Emergence of white-lie telling in children between 3 and 7 years of age." Merrill-Palmer Quarterly 48.2 (2002): 160-181.

Talwar, Victoria, Susan M. Murphy, and Kang Lee. "White lie-telling in children for politeness purposes." International journal of behavioral development 31.1 (2007): 1-11.

Thomas, Duncan. "Like Father, like Son; Like Mother, like Daughter: Parental Resources and Child Height." The Journal of Human Resources. (1994). Vol 29, No 4.

Tibbetts, Stephen G. "Differences between Women and Men regarding Decisions to Commit Test Cheating." Research in Higher Education 40, no. 3 (June 1999): 323-42. 
Uddin, Lucina Q., Jan Rayman, and Eran Zaidel. "Split-brain Reveals Separate but Equal Selfrecognition in the Two Cerebral Hemispheres." Consciousness and Cognition 14, no. 3 (2005): 633-40. doi:10.1016/j.concog.2005.01.008.

Vohs, Kathleen D., and Jonathan W. Schooler. "The Value of Believing in Free Will: Encouraging a Belief in Determinism Increases Cheating." Psychological Science 19, no. 1 (2008): 49-54. doi:10.1111/j.1467-9280.2008.02045.x.

Ward, David A., and Wendy L. Beck. "Gender and Dishonesty." The Journal of Social Psychology 130, no. 3 (1990): 333-39. doi:10.1080/00224545.1990.9924589.

Yang, Y. "Prefrontal White Matter in Pathological Liars." The British Journal of Psychiatry 187, no. 4 (2005): 320-25. doi:10.1192/bjp.187.4.320. 
Table 1: Summary of Treatments

\begin{tabular}{l|cc}
\hline & Parent \& Child Together & Parent Alone (Child out of the room) \\
\hline Prize for Parent & $\begin{array}{c}\text { PC_P - 58 parent-child pairs } \\
\text { (51 mother and 7 father pairs) }\end{array}$ & $\begin{array}{c}\text { Pa_P - 61 parent-child pairs } \\
\text { (56 mother and 5 father pairs) }\end{array}$ \\
Prize for Child & $\begin{array}{l}\text { PC_C - 66 parent-child pairs } \\
\text { (57 mother and 9 father pairs) }\end{array}$ & $\begin{array}{c}\text { Pa_C - 64 parent-child pairs } \\
\text { (59 mother and 5 father pairs) }\end{array}$ \\
\hline
\end{tabular}

Table 2: Summary Statistics

$\begin{array}{cccc}\text { Treatment } & \text { \% Mothers } & \text { \% Daughters } & \text { Child Age (Years) } \\ \text { PC_C } & 86.4 \% & 48.5 \% & 3.94(0.08) \\ \text { PC_P } & 87.9 \% & 51.7 \% & 4.00(0.09) \\ \text { Pa_C } & 92.2 \% & 53.1 \% & 4.16(0.08) \\ \text { Pa_P } & 91.8 \% & 45.9 \% & 4.06(0.09)\end{array}$

Note: $\%$ Mothers is the $\%$ of parents in the activity who are mothers, the remainder are fathers. \% Daughters is the $\%$ of girls in the activity, the remainder are boys. Child age is reported in years, with standard error in parentheses. T-tests comparing demographics by treatment do not show statistically significant differences, except child age between PC_C and Pa_C is marginally statistically significant $(p$-value $<0.10)$. 
Table 3: Winning Rates by Treatment

\begin{tabular}{lcccccc} 
Treatment & Observations & $\begin{array}{c}\text { Winning } \\
\text { Rate }\end{array}$ & $\begin{array}{c}\text { Compare } \\
\text { to PC_C }\end{array}$ & $\begin{array}{c}\text { Compare } \\
\text { to PC_P }\end{array}$ & $\begin{array}{c}\text { Compare } \\
\text { to Pa_C }\end{array}$ & $\begin{array}{c}\text { Compare } \\
\text { to Pa_P }\end{array}$ \\
\cline { 3 - 7 } PC_C & 66 & 0.35 & N/A & & & \\
PC_P & 58 & $0.36^{*}$ & & N/A & & \\
Pa_C & 64 & $0.50^{* * *}$ & $*$ & & N/A & \\
Pa_P & 61 & 0.33 & & & $*$ & N/A \\
\hline
\end{tabular}

Note: The probability of winning is $25 \%$ in all treatments. Statistically significant differences using a t-test from 0.25 for each treatment are indicated by * $(p<0.10) * *(p<0.05)$ and *** $(p<0.01)$. Columns 4-7 indicate statistically significant $\mathrm{Chi}^{\wedge} 2$ tests for each treatment comparison, using $*(p<0.10), * *(p<0.05)$ and $* * *(p<0.01)$. 
Table 4: Predictive Regressions of Winning (Logit with Experimenter Fixed Effects)

\begin{tabular}{|c|c|c|c|c|c|c|}
\hline & (1) & (2) & (3) & (4) & $(5)$ & (6) \\
\hline VARIABLES & $\begin{array}{l}\text { Reported } \\
\text { Win }\end{array}$ & $\begin{array}{l}\text { Reported } \\
\text { Win }\end{array}$ & $\begin{array}{l}\text { Reported } \\
\text { Win }\end{array}$ & $\begin{array}{l}\text { Reported } \\
\text { Win }\end{array}$ & $\begin{array}{l}\text { Reported } \\
\text { Win }\end{array}$ & $\begin{array}{l}\text { Reported } \\
\text { Win }\end{array}$ \\
\hline \multirow{2}{*}{$\begin{array}{l}\text { Child Present } \\
\text { Dummy }\end{array}$} & 0.113 & 0.119 & 0.818 & 0.831 & 0.825 & 0.442 \\
\hline & $(0.391)$ & $(0.391)$ & $(0.556)$ & $(0.557)$ & $(0.559)$ & $(2.384)$ \\
\hline \multirow{2}{*}{$\begin{array}{l}\text { Prize for Child } \\
\text { Dummy }\end{array}$} & $0.713^{*}$ & $0.698^{*}$ & $1.061^{*}$ & $1.068^{*}$ & $1.065^{*}$ & $5.438^{* *}$ \\
\hline & $(0.375)$ & $(0.376)$ & $(0.545)$ & $(0.546)$ & $(0.546)$ & $(2.486)$ \\
\hline \multirow[t]{2}{*}{ Interaction } & $-0.905^{*}$ & $-0.885^{*}$ & $-1.428^{*}$ & $-1.437 *$ & $-1.433 *$ & -4.732 \\
\hline & $(0.537)$ & $(0.538)$ & $(0.758)$ & $(0.759)$ & $(0.760)$ & (3.484) \\
\hline \multirow{2}{*}{$\begin{array}{l}\text { GECC Control } \\
\text { Group }\end{array}$} & -0.0313 & 0.0251 & -0.0346 & -0.0372 & -0.0361 & -0.0693 \\
\hline & $(0.280)$ & $(0.293)$ & $(0.299)$ & $(0.299)$ & $(0.299)$ & $(0.305)$ \\
\hline \multirow[t]{2}{*}{ Age at Activity } & & 0.138 & 0.133 & 0.143 & 0.142 & 0.404 \\
\hline & & $(0.210)$ & $(0.214)$ & $(0.216)$ & $(0.216)$ & $(0.394)$ \\
\hline \multirow[t]{2}{*}{ Female Child } & & & 0.562 & 0.568 & 0.433 & 0.623 \\
\hline & & & $(0.566)$ & $(0.565)$ & $(1.018)$ & $(1.020)$ \\
\hline \multirow[t]{2}{*}{ Prize*Female } & & & -0.745 & -0.760 & -0.760 & -0.945 \\
\hline & & & $(0.766)$ & $(0.766)$ & $(0.766)$ & $(0.783)$ \\
\hline \multirow{2}{*}{\multicolumn{7}{|c|}{ Present*Female }} \\
\hline & & & & & & \\
\hline & & & $(0.818)$ & $(0.819)$ & $(0.820)$ & $(0.838)$ \\
\hline \multirow[t]{2}{*}{ Interaction*Female } & & & 1.093 & 1.118 & 1.118 & 1.414 \\
\hline & & & (1.099) & $(1.101)$ & $(1.101)$ & $(1.125)$ \\
\hline \multirow[t]{2}{*}{ Mother } & & & & 0.163 & 0.0945 & 0.230 \\
\hline & & & & $(0.464)$ & $(0.630)$ & $(0.635)$ \\
\hline \multirow[t]{2}{*}{ Mother*Daughter } & & & & & 0.147 & 0.0166 \\
\hline & & & & & $(0.925)$ & $(0.922)$ \\
\hline \multirow[t]{2}{*}{ Child Present*Age } & & & & & & 0.122 \\
\hline & & & & & & $(0.571)$ \\
\hline \multirow[t]{2}{*}{ Prize*Age } & & & & & & $-1.035^{*}$ \\
\hline & & & & & & $(0.573)$ \\
\hline \multirow[t]{2}{*}{ Interaction*Age } & & & & & & 0.756 \\
\hline & & & & & & $(0.828)$ \\
\hline Observations & 249 & 249 & 249 & 249 & 249 & 249 \\
\hline $\begin{array}{c}\text { Number of } \\
\text { Experimenters }\end{array}$ & 8 & 8 & 8 & 8 & 8 & 8 \\
\hline
\end{tabular}

Note: The omitted treatment is Pa_P (Parent alone, Prize for parent). Child Present Dummy indicates PC_C and PC_P, Prize for child dummy indicates $\mathrm{Pa}_{-} \mathrm{C}$ and $\mathrm{PC} \mathrm{C}_{-}$and Interaction indicates the $\mathrm{PC} \mathrm{C}_{-}$treatment. Column (3) provides child-gender and treatment interactions, Columns (4)-(5) incorporate a dummy for whether the mother is participating, and a mother-daughter pair dummy, respectively. Finally, Column (6) includes age and treatment interactions. Since 8 different research assistants carried out the study, this regression uses research assistant fixed effects. Table 1A in Appendix C provides the same regression without fixed effects, obtaining qualitatively similar results. Standard errors in parentheses. ${ }^{* * *} \mathrm{p}<0.01,{ }^{* *} \mathrm{p}<0.05,{ }^{*} \mathrm{p}<0.1$ 
Table 5: Explanatory Variables

\begin{tabular}{|c|c|c|c|}
\hline VARIABLES & $\begin{array}{c}(1) \\
\text { Reported Win } \\
\end{array}$ & $\begin{array}{c}(2) \\
\text { Reported Win } \\
\end{array}$ & $\begin{array}{c}\text { (4) } \\
\text { Reported Win } \\
\end{array}$ \\
\hline Child Present Dummy & $\begin{array}{c}1.678 \\
(1.144)\end{array}$ & $\begin{array}{l}-0.222 \\
(1.472)\end{array}$ & $\begin{array}{l}-0.590 \\
(1.998)\end{array}$ \\
\hline Prize for Child Dummy & $\begin{array}{c}2.312 * * \\
(1.117)\end{array}$ & $\begin{array}{c}2.295 \\
(1.571)\end{array}$ & $\begin{array}{c}0.327 \\
(2.328)\end{array}$ \\
\hline Interaction & $\begin{array}{c}-3.195 * * \\
(1.628)\end{array}$ & $\begin{array}{l}-2.682 \\
(2.176)\end{array}$ & $\begin{array}{l}-0.553 \\
(3.218)\end{array}$ \\
\hline GECC Control Group & $\begin{array}{c}0.142 \\
(0.316)\end{array}$ & $\begin{array}{c}-0.00757 \\
(0.316)\end{array}$ & $\begin{array}{l}-0.0677 \\
(0.319)\end{array}$ \\
\hline Age at Activity & $\begin{array}{c}0.209 \\
(0.232)\end{array}$ & $\begin{array}{c}0.121 \\
(0.229)\end{array}$ & $\begin{array}{c}0.167 \\
(0.227)\end{array}$ \\
\hline $\begin{array}{l}\text { Female Child } \\
\text { Prize*Female }\end{array}$ & $\begin{array}{c}0.818 \\
(0.593) \\
-1.260\end{array}$ & $\begin{array}{c}0.464 \\
(0.601) \\
-3.105^{*}\end{array}$ & $\begin{array}{c}0.415 \\
(0.617) \\
-0.354\end{array}$ \\
\hline Child Present*Female & $\begin{array}{l}(1.374) \\
-2.951 * \\
(1.508)\end{array}$ & $\begin{array}{l}(1.693) \\
-2.018 \\
(1.932)\end{array}$ & $\begin{array}{c}(2.842) \\
1.490 \\
(2.502)\end{array}$ \\
\hline Interaction*Female & $\begin{array}{c}2.760 \\
(2.308)\end{array}$ & $\begin{array}{l}5.496^{*} \\
(2.917)\end{array}$ & $\begin{array}{l}-0.274 \\
(4.628)\end{array}$ \\
\hline Cognitive Score & $\begin{array}{c}0.0110 \\
(0.0127)\end{array}$ & & \\
\hline Child Present*Cognitive Score & $\begin{array}{l}-0.0178 \\
(0.0282)\end{array}$ & & \\
\hline Prize for Child*Cognitive Score & $\begin{array}{l}-0.0272 \\
(0.0244)\end{array}$ & & \\
\hline Interaction*Cognitive Score & $\begin{array}{c}0.0430 \\
(0.0402)\end{array}$ & & \\
\hline Child Present*Female*Cognitive Score & $\begin{array}{c}0.0259 \\
(0.0311)\end{array}$ & & \\
\hline Prize for Child*Female*Cognitive Score & $\begin{array}{c}0.0115 \\
(0.0272)\end{array}$ & & \\
\hline Interaction*Female*Cognitive Score & $\begin{array}{l}-0.0413 \\
(0.0513)\end{array}$ & & \\
\hline Child would tell a secret & & $\begin{array}{l}-0.358 \\
(0.376)\end{array}$ & \\
\hline Child Present*Child would tell a secret & & $\begin{array}{c}0.456 \\
(0.605)\end{array}$ & \\
\hline Prize for Child* child would tell a secret & & $\begin{array}{l}-0.526 \\
(0.664)\end{array}$ & \\
\hline Interaction*Child would tell a secret & & $\begin{array}{c}0.537 \\
(0.896)\end{array}$ & \\
\hline Child Present*Female*Child would tell a secret & & $\begin{array}{c}0.242 \\
(0.724)\end{array}$ & \\
\hline Prize for Child*Female*Child would tell a secret & & $\begin{array}{c}0.985 \\
(0.630)\end{array}$ & \\
\hline Interaction*Female*Child would tell a secret & & $\begin{array}{r}-1.884^{*} \\
(1.140)\end{array}$ & \\
\hline Child Conscientious & & & $\begin{array}{l}-0.537 \\
(1.782)\end{array}$ \\
\hline Child Present*Child Conscientious & & & $\begin{array}{c}2.066 \\
(2.605)\end{array}$ \\
\hline Prize for Child*Child Conscientious & & & $\begin{array}{c}0.992 \\
(3.013)\end{array}$ \\
\hline Interaction*Child Conscientious & & & $\begin{array}{l}-1.377 \\
(4.152)\end{array}$ \\
\hline Child Present*Female*Child Conscientious & & & $\begin{array}{l}-3.840 \\
(3.154)\end{array}$ \\
\hline Prize for Child*Female*Child Conscientious & & & $\begin{array}{l}-0.294 \\
(3.547)\end{array}$ \\
\hline Interaction*Female*Child Conscientious & & & $\begin{array}{c}1.623 \\
(5.852)\end{array}$ \\
\hline Observations & 236 & 237 & 241 \\
\hline Number of assessor & 8 & 8 & 8 \\
\hline
\end{tabular}


Figure 1: Rates of Winning by Gender of the Child

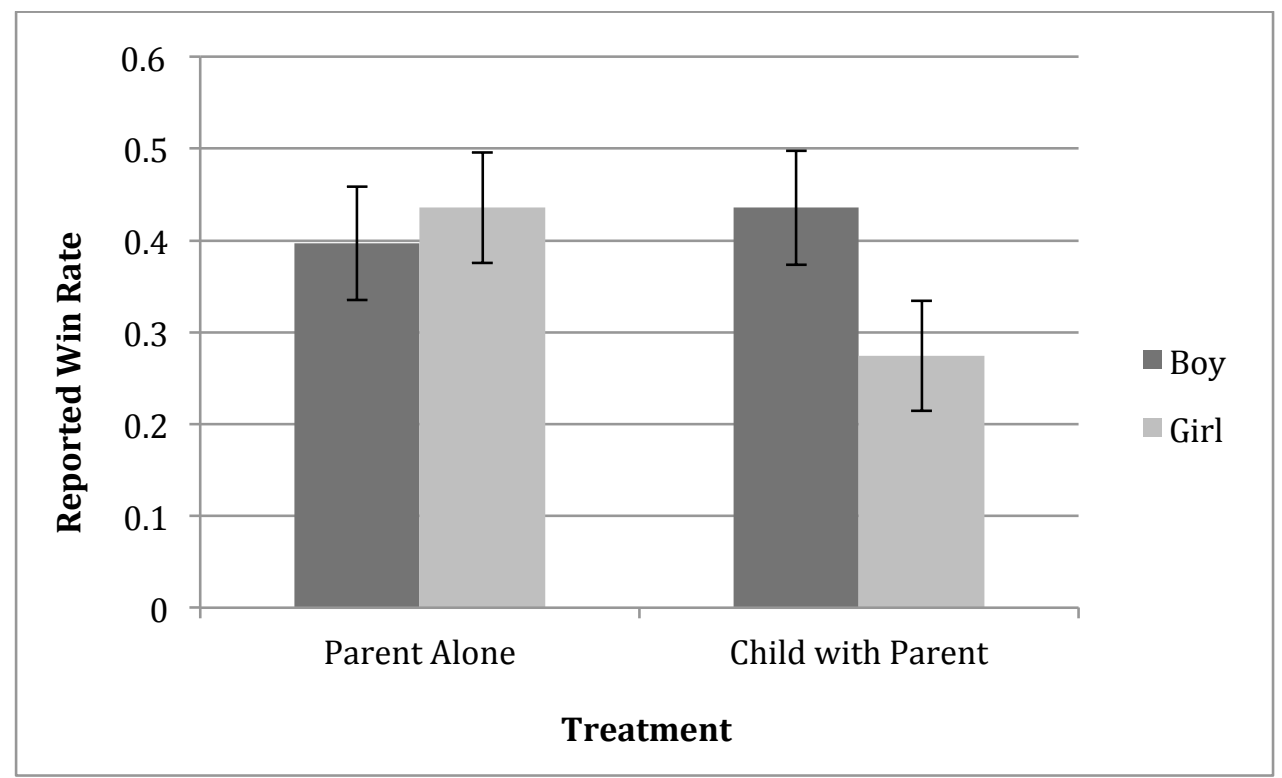

Note: This figure shows the winning rate for pairs with girl or boy children, separately for the $\mathrm{Pa}$ _P and $\mathrm{Pa}{ }_{-} \mathrm{C}$ treatments versus $\mathrm{PC} \mathrm{C}_{-}$and $\mathrm{PC} \mathrm{P}_{-} \mathrm{P}$ treatments. Standard error bars are included. 


\section{APPENDICES FOR WEB ONLY}

\section{Appendix A: Description of Study Environment}

\section{A.1. Griffin Early Childhood Center (GECC) Laboratory}

The studies were conducted at the Griffin Early Childhood Center (GECC) on July 26 and 27 in 2011 (Highland Campus Preschool). The GECC program was launched in August, 2010 and serves as a 'laboratory' for experiments of this sort. The GECC itself is a randomized field experiment testing the effects of different early childhood intervention programs for 3-5 year old children. Families from the 2010-11 and 2011-12 GECC cohorts were invited to participate in this incentivized "parent-child activity."15 When participants are recruited into GECC, the optional activities that are part of the program are explained. Participants did not know what the activity was about when they signed up. Parents were told that they would receive $\$ 10$ just for coming, and have the chance to earn more prizes, for a "Coin Toss Activity" that would take around 15-20 minutes of their time. Some parents and children had previously participated in activities that are unrelated to this project.

At GECC, a standardized system is in place for recruitment. Each prospective participant receives a flyer describing the length of the study, who can participate, and the show up fee. Each participant then receives up to 2 emails asking if he/she would like to set up an appointment. The day before the appointment, the parent receives a reminder call and at that time can change the appointment time. Parents who do not show up receive a call asking if they would like to reschedule (if slots are available only).

\section{A. 2. Environment Setup}

We followed a standard procedure developed at GECC to conduct the study. Most experiments involving children at GECC are conducted one-on-one with the experimenter - in this case, the parent-child pair participated in the experiment with one experimenter assigned to each pair. Thus, in a sense there were 152 separate sessions of the experiment. One of the authors was in charge of implementing the study, including training staff, monitoring recruitment, observing the staff during the duration of the experiment, and monitoring data entry. We used 8

\footnotetext{
${ }^{15}$ Note that the GECC was renamed to CHECC (Chicago Heights Early Childhood Center) in 2012, and is now known by the new name.
} 
different experimenters, who were all Research Assistants or full time staff at the University of Chicago working for the author and have experience in conducting other experiments at GECC. 5 of the experimenters were male, and 3 of the experimenters were female. 2 of the experimenters were fluent in Spanish, and conducted the experiment in Spanish for the Spanishspeaking parent-child pairs. The remaining experimenters conducted the experiment in English. The study also required the use of several waiting area assistants and babysitters, and check-in staff, who were also Research Assistants at the university or interns at the GECC.

\section{A.3. Procedure}

The parent/child pairs arrived at their appointment time to the sign-in desk, and were escorted to the waiting area, which had drawing activities available for children. Parent-child pairs who arrived with multiple parents (or multiple children) were asked to select which childparent pair will participate in the study. We recorded whether the mother or father participated as the parent. We do have some cases where two parents came with two children, in which case we have observations for 2 separate parent-child pairs within one family unit.

After the child felt comfortable in the environment, a waiting area assistant confirmed language preference and escorted the child to the next available experimenter. The waiting area assistant asked, "Are you ready to do the activity? I'm going to introduce you to my friend, do you want to come with me?" No child refused to do the activity. The matching of parent-child pairs to experimenter was random, since experimenters did not choose the pair and we were careful to instruct the waiting area assistant to bring the pair to the next available experimenter of the appropriate language.

Experimenters were given a schedule at the beginning of Day 1 that determined the random order in which they were to conduct the treatments. Different experimenters had different schedules in order to assure that different treatments were conducted on different times of the day. The callers who scheduled participants to session slots were not aware of the treatment schedule, and waiting room assistants were not aware of which experimenter was conducting which treatment at any one time, so assignment to treatment was also random.

Each experimenter had his/her own station, and experimenters were randomly assigned to stations on Day 1 and switched on Day 2. The Highland Campus Preschool consists of 5 large classrooms and two smaller experimentation rooms. For this experiment, 2 separate stations were 
created in each of 4 classroom using desks and room dividers to assure privacy, and 1 station was created in one of the smaller rooms, for a total of 13 stations.

Experiment instructions are available below. For consistency across experimenters, we employed a semi-automated procedure. The experimenter sat across from a laptop screen and next to the parent-child pair. Prior to the experimental sessions, we recorded the instructions in a video format, in which the experimenter acted as the "Activity Leader," while the character on the screen (played by one of the authors for the English version and a translator in the Spanish version) in the video explained the instructions to the parent-child pair out loud. The character on the screen was female in both the English and Spanish translation. No written instructions were distributed to parents. The instructions were interactive to assure understanding, involving stopping points in which the video character asked the child to repeat back an answer (.e.g., "What happens if both coins land green side up?). At these points, the Activity Leader stopped the video and asked the child to tell him/her the answer. Correction was done as needed, and parents were allowed to have their questions answered about the instructions at the end of the video demonstration (but not about the purpose of the experiment).

At one point during the video, the Activity Leader also displayed the appropriate prize incentive to subjects - several prizes were arranged in a clear box. The instructions also included a demonstration of the correct way to toss the coin, which was demonstrated both on-screen by the video character and in person by the Activity Leader. Finally, the parent was also asked to try a practice coin toss. ${ }^{16}$

After the instructions were read, the experimenter left the room (with or without the child, depending on treatment). The parent was instructed to flip the coin, record the outcome on the outcome sheet, and call for the experimenter when finished. The experimenter returned to the room either after approximately 5 minutes or after the parent came to the door to call for the experimenter. The experimenter checked to see if the parent-child pair won a prize, and if so, gave the prize to the parent-child pair. Then the experimenter gave the parent a short questionnaire to fill out in the waiting area at the completion of the study.

After the parent completed the questionnaire, the family proceeded to the check-out desk to receive the $\$ 10$ show up fee and sign out, and then left. Each child also received a small

\footnotetext{
16 The practice toss was conducted because during the pilot, parents complained about not knowing the "right" way to toss the coin. Thus, we devised a simple way to toss the coin that all parents were asked to follow.
} 
"show up fee" regardless of the outcome of the coin toss, and was allowed to pick out one or two small items from a clear box containing stickers, small candies, and erasers. The child was told about the show up fee at the beginning of the experiment instructions - "at the end of the game you will get some stickers for playing the game, ok? So pay attention to the rules!"

The parent-child pairs who completed the study generally did not interact with the parentchild pairs who had just arrived, primarily because the parents who had just completed the experiment were completing the surveys and getting ready to check out so that they could receive the $\$ 10$ show up fee, and the new arrivals were promptly getting assigned to an experiment station and leaving the waiting area. We did have assistants in the waiting area at all times, and we never noted any discussion of the experiment design or outcome.

\section{Appendix B: Experiment Instructions (Child Prize, Parent and Child Together - PC_C)}

\section{STAGE 1: GREETING}

Hello! I'm Miss Anya! And this is Mr. Teddy Bear! Nice to meet you! in Spanish: Hola, me llamo Jennie!

First of all, thanks for playing with us today. Teddy and I are going to help your Activity Leader today. I'm going to be talking to the kid in the room, so if I say YOU that means YOU, and if I say your parent, that means your mom or dad, okay?

[To child] At the end of the game, you will get some stickers and a candy for playing the game. Okay? So pay attention to the rules!

Also, today there will be the chance to win an extra prize.

\section{STAGE 2: GAME}

[To parent] Here is the sheet that your parent will take notes on for the game. In this game, you are going to toss two coins to find out whether you will win a prize.

We will use two coins like this, with a blue and a green face (show coins) Leader, can you show the coins? 
Both of you have a different job to do. Please only do the job that we ask you, okay?

[To Parent] Your parent is going to toss both of the coins. Then your parent is going to record the outcome on the sheet. Leader, can you show on the sheet while I talk about it? YOU get a prize if both coins land on GREEN, but you do NOT get a prize if each coin lands on a different color or if both coins land on BLUE. That means if both coins land GREEN side up, you will get a prize. But, if both coins land BLUE side up, you will not get a prize. And, if one coin lands BLUE side up but the other coin lands GREEN side up, you will not get a prize. When the coin toss is done, your parent is going to record the outcome on the recording sheet.

[To Child] Your job is going to be to match some cards to the side the coin lands on. You get 4 cards - two BLUE and two GREEN. Leader, can you show the cards? Great. Hold on to them. When your mom/dad tosses the coins, see whether they landed BLUE or GREEN up. Then put the two cards that match the coin toss on the table. If both coins land BLUE side up, you put up both BLUE cards. Leader, can you show that? If both coins land GREEN side up, you put up both GREEN cards. Leader, can you show that? But if one coin lands BLUE side up and the other coin lands GREEN side up, you put up a green card and a blue card. Leader, can you show that? Your second job will be to hand the sheet your mom/dad filled out back to me. Leader, can you show the sheet again?

\section{Question Set 1}

Now, do you remember whose job it is to toss the coins? [Parent's job]

Do you remember whose job it is to match the cards? [child's job]

Will you stay with your parent or go with the leader for the next part? [Stay]

Whose job is it to hand the outcome sheet back to me? [Child's job]

\section{STAGE 3: THE OUTCOME}

Now let's talk about how to record the outcome. On this sheet, your parent is going to circle what happened. GREEN means that both coins landed on GREEN and then you [child] get a prize. BLUE means that both coins landed on BLUE, and DIFFERENT means each coin landed 
on a different color and then you [child] do not get a prize.

Let's see an example. If the Leader tossed the coins and got TWO GREEN, the Leader will circle this outcome [GREEN]. Leader, please show what you would circle! Then, we know that the Leader will get a prize. But if the Leader tossed the two coins and got ONE BLUE and ONE GREEN, the Leader will circle this outcome. Then, we know that the Leader will not get a prize. Leader, please show what you would circle! [Demonstrate on a laminated sample sheet].

\section{Question Set 2}

[To child] Now, if your mom/dad tossed two coins and got TWO BLUE, can you point to the outcome that he/she would circle? [ask child to point. That's right, or No, its this one. And this means there would not be a prize]

[To Child] Now, if I tossed two coins and got one blue and one green, which cards are you going to put on the table? [That's right, this card and this card. / No, you put this card and this card.]

Now, remember - if both coins land on GREEN, do you get a prize or not? [Yes, that's right, you get a prize / or No, if both coins are GREEN color, that means you will not get a prize.

But if both coins land on BLUE, do you get a prize or not? [That's right, you don't get a prize /or No, you don't get a prize, you only get a prize if they both land GREEN side up.]

But if one coin lands on BLUE, and one coin lands on GREEN, do you get a prize or not? [That's right, you don't get a prize /or No, you don't get a prize, you only get a prize if they both land GREEN side up.]

\section{STAGE 4: PRIZES}

Now let's see the prizes you can get. 
Leader, please show the prizes! If you win the game, you can pick from one of these prizes [show a bin of several different toys].

But remember, no matter what is the outcome, you will get stickers and a candy for doing a good job in the game.

\section{STAGE 5: PLAYING THE GAME}

Now the Leader is going to show your parent how to flip the coin and then the leader will leave the room. Please flip the coin the way the leader showed you, it is the easiest way. And only flip each coin one time. Hold the coin in your palm like this, and then toss it up in the air, like this and let it land on the table.

Go ahead and give it a try. (Great, you flipped it correctly/ or No, please flip it like this and try again). Leader, did they do it correctly?

How many times should your parent flip each coin? (That's right, you should only flip each coin one time / or You should flip each coin just one time, okay?)

Nobody except you and your parent will see the outcome of the coin toss. After your parent is done doing the coin toss and recording the outcome, your parent should go ahead and put the coins and cards back in this bin. Then your parent should give you the outcome sheet to show the leader. After the Leader gets back, the Leader will ask you to give back the outcome sheet and will look on the outcome sheet to see if you won a prize or not.

\section{Question Set 3}

Do you remember, who will see the outcome of the coin toss? [That's right, only you will see the outcome. I won't see the outcome. / or, No, I won't see the outcome, only you will see the outcome] 
You will have 5 minutes to play the game. The leader will leave the room. If you finish early, just buzz the buzzer and the leader will come back!

Great, see you soon!

\section{STAGE 7: RESULTS}

Hello, I am back. [You won a prize/ or You didn't win a prize]. Can you please fill out this short questionnaire before you leave? Thank you for playing the game. 
PID:

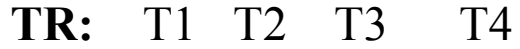

Date:

Time:

Activity Leader:

Outcome Sheet - Coin Toss Activity

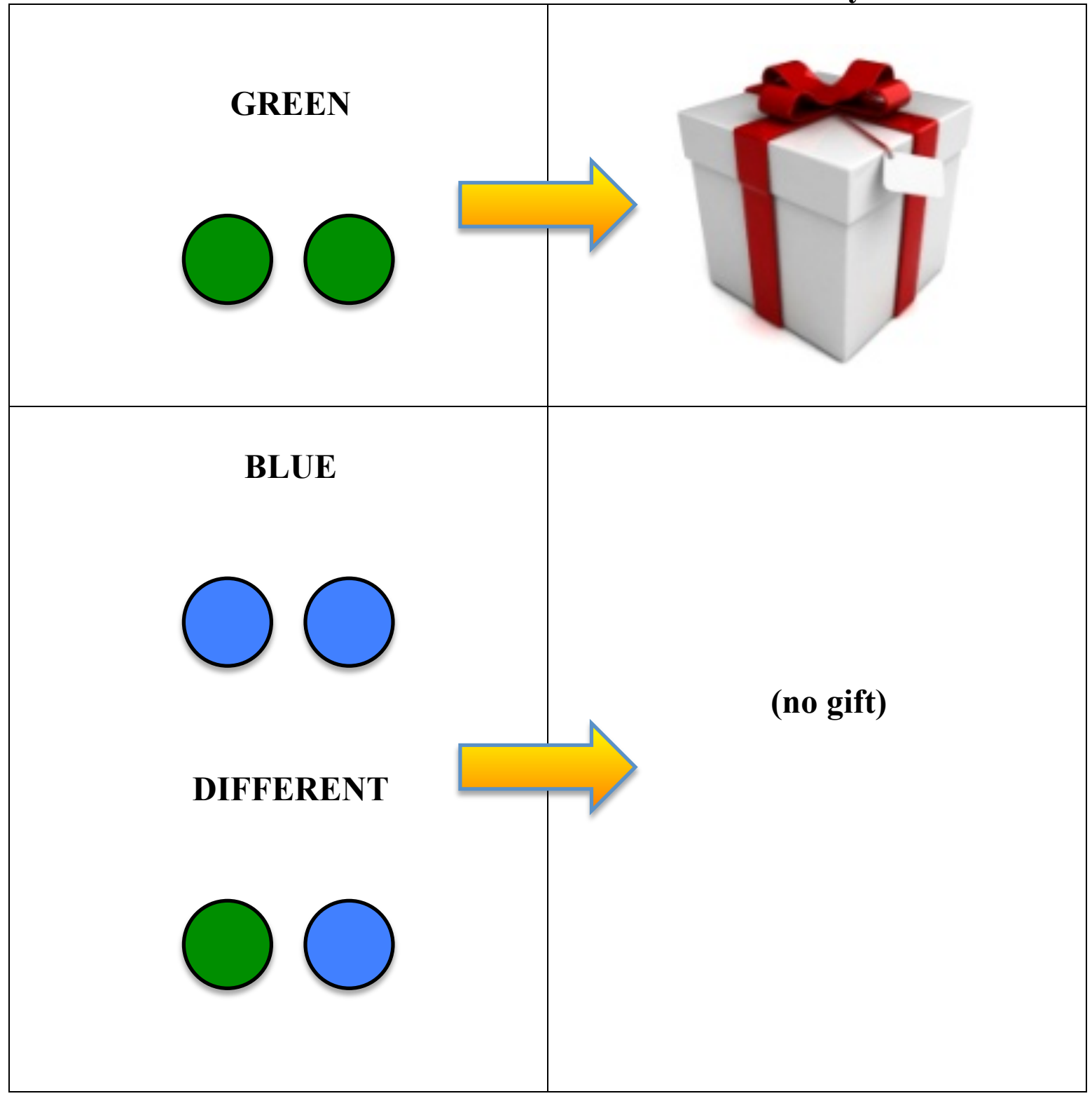

Child will hand outcome sheet to the activity leader!

1. Did you child do the card task right?
a. Yes, without my help
b. Yes, but she needed my help
c. She did not do the card task 


\section{Table 1A: Predictive Regressions of Winning (Logit without Experimenter Fixed Effects)}

\begin{tabular}{|c|c|c|c|c|c|}
\hline VARIABLES & $\begin{array}{c}\text { (1) } \\
\text { Reported } \\
\text { Win } \\
\end{array}$ & $\begin{array}{c}\quad(2) \\
\text { Reported } \\
\text { Win } \\
\end{array}$ & $\begin{array}{c}\text { (3) } \\
\text { Reported } \\
\text { Win } \\
\end{array}$ & $\begin{array}{c}\text { (4) } \\
\text { Reported } \\
\text { Win } \\
\end{array}$ & $\begin{array}{c}\quad(5) \\
\text { Reported } \\
\text { Win }\end{array}$ \\
\hline Child Present Dummy & $\begin{array}{c}0.156 \\
(0.386)\end{array}$ & $\begin{array}{c}0.872 \\
(0.548)\end{array}$ & $\begin{array}{c}0.895 \\
(0.550)\end{array}$ & $\begin{array}{c}0.900 \\
(0.552)\end{array}$ & $\begin{array}{c}0.403 \\
(2.337)\end{array}$ \\
\hline Prize for Child Dummy & $\begin{array}{l}0.722 * \\
(0.370)\end{array}$ & $\begin{array}{l}1.122^{* *} \\
(0.537)\end{array}$ & $\begin{array}{l}1.131^{* *} \\
(0.538)\end{array}$ & $\begin{array}{l}1.133^{* *} \\
(0.538)\end{array}$ & $\begin{array}{l}4.765^{* *} \\
(2.429)\end{array}$ \\
\hline Interaction & $\begin{array}{l}-0.787 \\
(0.528)\end{array}$ & $\begin{array}{l}-1.346^{*} \\
(0.745)\end{array}$ & $\begin{array}{l}-1.361 * \\
(0.746)\end{array}$ & $\begin{array}{l}-1.365^{*} \\
(0.747)\end{array}$ & $\begin{array}{l}-3.982 \\
(3.430)\end{array}$ \\
\hline GECC Control Group & $\begin{array}{l}-0.116 \\
(0.271)\end{array}$ & $\begin{array}{l}-0.161 \\
(0.284)\end{array}$ & $\begin{array}{l}-0.164 \\
(0.285)\end{array}$ & $\begin{array}{l}-0.164 \\
(0.285)\end{array}$ & $\begin{array}{l}-0.180 \\
(0.289)\end{array}$ \\
\hline Age at Activity & & $\begin{array}{l}0.0382 \\
(0.206)\end{array}$ & $\begin{array}{l}0.0529 \\
(0.208)\end{array}$ & $\begin{array}{l}0.0542 \\
(0.208)\end{array}$ & $\begin{array}{c}0.264 \\
(0.384)\end{array}$ \\
\hline Female Child & & $\begin{array}{c}0.578 \\
(0.553)\end{array}$ & $\begin{array}{c}0.592 \\
(0.554)\end{array}$ & $\begin{array}{c}0.704 \\
(0.991)\end{array}$ & $\begin{array}{c}0.834 \\
(0.998)\end{array}$ \\
\hline Prize*Female & & $\begin{array}{l}-0.812 \\
(0.746)\end{array}$ & $\begin{array}{l}-0.832 \\
(0.747)\end{array}$ & $\begin{array}{l}-0.832 \\
(0.748)\end{array}$ & $\begin{array}{l}-0.990 \\
(0.762)\end{array}$ \\
\hline Child Present*Female & & $\begin{array}{l}-1.468^{*} \\
(0.791)\end{array}$ & $\begin{array}{l}-1.493 * \\
(0.793)\end{array}$ & $\begin{array}{l}-1.498^{*} \\
(0.794)\end{array}$ & $\begin{array}{c}-1.604^{* *} \\
(0.805)\end{array}$ \\
\hline Interaction*Female & & $\begin{array}{c}1.106 \\
(1.072)\end{array}$ & $\begin{array}{c}1.146 \\
(1.075)\end{array}$ & $\begin{array}{c}1.145 \\
(1.075)\end{array}$ & $\begin{array}{c}1.367 \\
(1.091)\end{array}$ \\
\hline Mother & & & $\begin{array}{c}0.223 \\
(0.450)\end{array}$ & $\begin{array}{c}0.281 \\
(0.619)\end{array}$ & $\begin{array}{c}0.399 \\
(0.628)\end{array}$ \\
\hline Mother*Daughter & & & & $\begin{array}{l}-0.122 \\
(0.891)\end{array}$ & $\begin{array}{l}-0.215 \\
(0.894)\end{array}$ \\
\hline Child Present*Age & & & & & $\begin{array}{c}0.141 \\
(0.559)\end{array}$ \\
\hline Prize*Age & & & & & $\begin{array}{l}-0.857 \\
(0.560)\end{array}$ \\
\hline Interaction*Age & & & & & $\begin{array}{c}0.598 \\
(0.817)\end{array}$ \\
\hline Constant & $\begin{array}{c}-0.674 * * \\
(0.290)\end{array}$ & $\begin{array}{l}-1.092 \\
(0.961)\end{array}$ & $\begin{array}{l}-1.362 \\
(1.105)\end{array}$ & $\begin{array}{l}-1.422 \\
(1.189)\end{array}$ & $\begin{array}{l}-2.405 \\
(1.796)\end{array}$ \\
\hline Observations & 249 & 249 & 249 & 249 & 249 \\
\hline
\end{tabular}

Note: This table replicates Table 4 in the paper, without experimenter fixed effects. The omitted treatment is Pa_P (Parent alone, Prize for parent). Child Present Dummy indicates PC_C and PC_P, Prize for child dummy indicates $\mathrm{Pa} \_\mathrm{C}$ and $\mathrm{PC} \_\mathrm{C}$ and Interaction indicates the $\mathrm{PC} \_\mathrm{C}$ treatment. Column (3) provides child-gender and treatment interactions, Columns (4)-(5) incorporate a dummy for whether the mother is participating, and a mother-daughter pair dummy, respectively. Finally, Column (6) includes age and treatment interactions. Standard errors in parentheses. ${ }^{* * *} \mathrm{p}<0.01,{ }^{* *} \mathrm{p}<0.05,{ }^{*} \mathrm{p}<0.10$. 